\title{
PENGETAHUAN IBU RUMAH TANGGA TENTANG MENYIKAT GIGI SECARA DINI PADA ANAK TERHADAP NILAI def-t DI TK-ISLAM TERPADU RA. AL-HASANAH JL. BUNGA MELATI KECAMATAN MEDAN TUNTUNGAN
}

\author{
Susy Adrianelly \\ Jurusan Keperawatan Gigi Poltekkes Kemenkes Medan
}

\begin{abstract}
Abstrak
Pengetahuan orang tua sangat penting untuk mendasari terbentuknya perilaku yang mendukung kebersihan gigi dan mulut anak. Pengetahuan di peroleh melalui penginderaan terhadap objek tertentu untuk terbentuknya suatu tindakan. Pengetahuan dapat di peroleh secara alami maupun terencana yaitu melalui proses pendidikan. Peran orang tua, khususnya ibu sangat diperlukan didalam membimbing, memberikan pengertian, menyediakan sikat gigi anak dan mengajarkan cara menyikat gigi secara dini, Sikat gigi merupakan suatu alat untuk membersihkan gigi,menyikat gigi dapat menjaga kebersihan gigi dan mulut serta menghindari terbentuknya lubang gigi serta penyakit gigi. Jenis penelitian yang digunakan adalah penelitian deskriptif dengan metode survey yang bertujuan untuk mengetahui pengetahuan ibu rumah tangga tentang menyikat gigisecara dini pada anak terhadap nilai def-t di TK Islam Terpadu RA Al Hasanah Jalan Bunga Melati Medan Tuntungan. Data diperoleh secara langsung melalui kuesioner yang diberikan kepada responden dan diolah secara manual. Sampel penelitian adalah 31 orang. Berdasarkan hasil penelitian, diperoleh ibu yang memiliki pengetahuan dengan kriteria baik ada 25 orang (83,3\%), lima orang yang memiliki kriteria sedang (17\%) dan tidak ada yang memiliki kriteria buruk dalam tikat pengetahuan ibu. Hasil penelitian dapat disimpulkan bahwa pengetahuan ibu tentang menyikat gigi secara dini pada anak dikategorikan baik sebayak 25 (83,3\%), lima orang yang memiliki kategori sedang (17\%) dan tidak ada yang memiliki kategori buruk dalam tikat pengetahuan ibu. Nilai def-t yaitu kategori gigi yang berlubang atau decay 91 (3,6\%), kategori gigi yang dicabut karena karies dankarena sebab lain atau extraction 29 (96,6\%).
\end{abstract}

Kata kunci : Pengetahuan, Menyikat Gigi Secara Dini, Def-t

\section{Latar Belakang}

Kesehatan menurut WHO diartikan sebagai keadaan baik secara menyeluruh termasuk kondisi fisik, mental dan sosialnya, tidak sekedar ketiadaan suatu penyakit atau kecacatan.Dalam pengertian kesehatan seperti inilah setiap kondisi lingkungan yang berpengaruh kepada gangguan fisik, mental, dan sosial seseorang pada dasarnya adalah pengaruh lingkungan terhadap kesehatan.

Kesehatan merupakan bagian penting dari setiap kehidupan manusia.Pemerintah membuat suatu program yang bertujuan untuk mengubah perilaku masyarakat kearah perilaku sehat, yang ini merupakan salah satu faktor pendukung untuk mencapai kesehatan yang optimal.Prilaku sehat dan kemampuan masyarakat untuk memilih dan mendapatkan pelayanan kesehatan yang bermutu sangat menentukan pembangunan kesehatan.

Pembangunan kesehatan bertujuan meningkatkan kesadaran kemauan,serta kemampuan hidup sehat bagi setiap orang agar terwujud derajat kesehatan yang optimal.Oleh karna itu perlu perwujudan paradigma sehat yang mengutamakan pencegahan (preventif), meningkatkan kesehatan (promotif) serta upaya peningkatan (kuratif) dan pemulihan kesehatan (rehabilitatif).

Tubuh yang sehat tidak lepas dari keadaan rongga mulut yang sehat,kesehatan rongga mulut merupakan bagian integeral dari kesehatan manusia seutuhnya juga dalam meningkatkan kualitas dan produktivitas sumber daya manusia.Walaupun demikian bayak juga yang tidak tahu bahwa rongga mulut yang berperan penting dalam kesehatan tubuh.

Menurut data Riset Kesehatan Dasar (Riskedas) tahun 2007, penduduk Indonesia75\%mengalami riwayat karies gigi dengan tingkat keparahan gigi sebanyak lima gigi setiap orang. Hanya 7\% penduduk yang menyikat gigi dengan benar dan 7\% masyarakat yang bersedia berobat gigi. Dapat dibayangkan betapa besar pelayanan kesehatan gigi apabila masyarakat menyadari penyakitnya dan datang berobat ke pelayanan kesehatan gigi. Lebih terlihat lagi dari rendahnya kemauan masyarakat yang memanfaatkan jasa pelayanan kesehatan gigi.

Pengetahuan orang tua sangat penting untuk mendasari terbentuknya perilaku yang mendukung kebersihan gigi dan mulut anak.Pengetahuan di peroleh melalui penginderaan terhadap objek tertentu untuk 
terbentuknya suatu tindakan. Pengetahuan dapat di peroleh secara alami maupun terencana yaitu melalui proses pendidikan. Peran orang tua,khususnya ibu sangat diperlukan didalam membimbing, memberikan pengertian, menyediakan sikat gigi anak dan mengajarkan cara menyikat gigi secara dini, Sikat gigi merupakan suatu alat untuk membersihkan gigi,menyikat gigi dapat menjaga kebersihan gigi dan mulut serta menghindari terbentuknya lubang gigi serta penyakit gigi.

Berdasarkan alasan di atas maka penulis tertarik melakukan penelitian penelitian gambaran pengetahuan ibu rumah tangga menyikat gigi secara dini pada anak terhadap nilai def-t di TK-Islam Terpadu Ra.Al-Hasanah Jl.Bunga Melati Kemenangan Tani Kecamatan Medan Tuntungan 2018.

\section{Perumusan Masalah.}

Berdasarkan latar belakang, maka yang menjadi rumusan masalah adalah bagaimana gambaran pengetahuan ibu rumah tangga tentang menyikat gigi secara dini pada anak terhadap nilai def-t di TK-Islam Terpadu RA Al-Hasanah Jl.Bunga MelatiKecamatan Medan tuntungan.

\section{Tujuan Penelitian}

Penelitian dilakukan bertujuan untuk mengetahui pengetahuan ibu tentang menyikat gigi secara dini pada anak terhadap nilai def-t di TK-Islam Terpadu RA AlHasanah 2018.

\section{Manfaat Penelitian}

Data yang diperoleh dari penelitian diharapkan dapat digunakan:

1. Untuk menambah wawasan dan pengetahuan ibu tentang menyikat gigi secara dini pada anak.

2. Menjadi masukan bagi pihak sekolah dalam melaksanakan program upaya kesehatan gigi di TK-Islam Terpadu Ra.Al-Hasanah.

3. Hasil penelitian ini diharapkan dapat menjadi sebagai bahan masukan dan sumber pengetahuan bagi peneliti selanjutnya.

\section{Kerangka Konsep}

Kerangka konsep diturunkan dari kerangka teori yang tujuannya adalah untuk mengetahui tingkat pengetahuan ibu rumah tangga tentang menyikat gigi secara dini pada anak terhadap nilai def-t berdasarkan kerangka konsep.

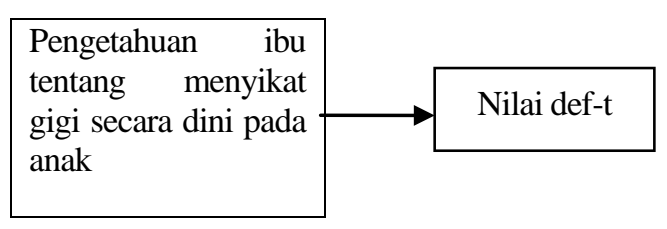

\section{Definisi Operasional}

Tingkat pengetahuan ibu tentang menyikat gigisecara dini adalah seberapa besar pemahaman ibu tentang pentingnyamenyikat gigi secara dini pada anak.
3. Menyikat gigi adalah tindakan membersihkan gigi yangmenggunakan alat sikat gigi yang dilakukansehari-hari.

4. Def-tadalah indeks pengukuran status karies gigi pada gigi sulung.

\section{Lokasi Penelitian}

Lokasi penelitian ini dilakukan di TK-Islam Terpadu Ra.Al-Hasanah Jl.Bunga Melati Kemenangan Tani Kecamatan Medan Tuntungan Tahun 2018.

\section{PopulasiPenelitian}

Menurut Notoadmodjo (2007) populasi adalah keseluruhan objek penelitian yang diteliti.

Populasi dalam penelitian adalah ibu-ibu yang memiliki anak bersekolah di TK-Islam Terpadu Ra.Al-Hasanah Jl.Bunga Melati Kemenangan Tani Kecamatan Medan Tuntungan dengan jumlah total populasi adalah31 orang.

\section{Sampel Penelitian}

Sampel penelitian adalah total populasi yang berjumlah 31 orang.

\section{Metode Pengumpulan Data}

Jenis data yang digunakan dalam penelitian adalah data primer, yang diperoleh langsung dari responden. Kuesioner di bagikan langsung kepada ibu atau dititipkan kepada anak disaat penjemput anak pulang sekolah dandibawa kembali pada esok hari. Kuesioner digunakan untuk mengetahui data pengetahuan ibu tentang menyikat gigi secara dini pada anak. Data def-t diperoleh langsung dari hasil pemeriksaan gigi anak. Jumlah pertanyaan dalam kuesioner terdiri dari 15 pertanyaan .

\section{Hasil Penelitian}

Hasil penelitian tentang gambaran pengetahuan ibu rumah tangga menyikat gigi secara dini pada anak terhadap nilai def-t di TK-Islam Terpadu Ra.Al-Hasanah Jl.Bunga Melati Kemenangan Tani Kecamatan Medan Tuntungan 2018, diperoleh sebagai berikut.

Tabel 1. Distribusi frekuensi tingkat pengetahuanibu rumah tangga menyikat gigi secara dini pada anak di TK-Islam Terpadu Ra.Al-Hasanah Jl.Bunga Melati Kemenangan Tani Kecamatan Medan Tuntungan Tahun 2018.

\begin{tabular}{|l|l|l|l|}
\hline No & $\begin{array}{l}\text { Kriteria } \\
\text { Pengetahuan }\end{array}$ & $\begin{array}{c}\text { Sampel } \\
\text { (n) }\end{array}$ & Persentase (\%) \\
\hline 1 & Baik & 25 & 83,3 \\
\hline 2 & Sedang & 5 & 17 \\
\hline 3 & Buruk & - & - \\
\hline Jumlah & 30 & 100 \\
\hline
\end{tabular}

Dari tabel 1 dapat dilihat bahwa ibu yang memiliki pengetahuan dengan kriteria baik ada 25 orang (83,3\%), lima orang yang memiliki kriteria sedang (17\%) dan tidak ada yang memiliki kriteria buruk dalam tikat pengetahuan ibu. 
Tabel 2. Distribusi frekuensi nilai def-t di TK-Islam Terpadu Ra.Al-Hasanah Jl.Bunga Melati Kemenangan Tani Kecamatan Medan Tuntungan Tahun 2018.

\begin{tabular}{|l|l|r|c|c|}
\hline No & Status Gigi & jumlah & $\begin{array}{c}\text { Sampel } \\
\text { (n) }\end{array}$ & $\begin{array}{c}\text { Persentase } \\
\text { (\%) }\end{array}$ \\
\hline 1 & decay (d) & 91 & 30 & 3,6 \\
\hline 2 & extraction (e) & 29 & 20 & 96,6 \\
\hline 3 & filling (f) & 0 & 0 & 0 \\
\hline
\end{tabular}

Dari tabel diatas, terlihat bahwa nilai def-t pada anak Tk-Islam Terpadu RA Al-Hasanah dengan kategori gigi yang berlubang / decay 91 (3,6\%), kategori gigi yang dicabut karena karies dankarena sebab lain / extraction 29 (96,6\%), dan kategori filling tidak ada ditemukan.

\section{Pembahasan}

Berdasarkan data yang telah diperoleh langsung dari 30 responden tentang pengetahuan ibu rumah tangga menyikat gigi secara dini pada anak dan nilai def-t di TKIslam Terpadu Ra.Al-Hasanah Jl.Bunga Melati Kemenangan Tani Kecamatan Medan Tuntungan Tahun 2018.

1. Dari tabel 1 daftar frekuensi pengetahuan ibu rumah tangga tentang menyikat gigi secara dini pada anak memperoleh kriteria baik yaitu sebanyak 25 orang $(83,3 \%)$ dan kriteria sedang sebanyak 5 orang (17\%). Berdasarkan data yang diperoleh dari ibu rumah tangga telah berpengetahuan baik tentang pentingnya menyikat gigi sejak dini pada anak sebanyak 30 (100\%). Meski demikian masih ada 24 ibu rumah tangga (80\%) belum mengetahui bahwa cara menyikat gigi geraham dataran pengunyahan yaitu dengan cara memutar. Menurut Ginandjar.R (2018) cara menyikat gigi yang baik adalah menggosokkan sikat gigi mulai dari gigi belakang kanan atau kiri di gerakkan kearah depan dan berakhir pada gigi belakang kanan atau kiri, dan untuk gigi geraham dataran pengunyahan (oklusal) dengan gerakan maju mundur. Terdapat 10 ibu rumah tangga (33,3\%) tidak mengetahui bahwa menyikat gigi tidak perlu dengan gerakan yang kuat. Rahmadhan, AG (2010) berpendapat bahwa dalam menyikat gigi tidak diperlu tekanan yang kuat karena sisa makanan masih memiliki konsistensi yang lunak sehingga mudah di bersihkan. Dan 15 1bu rumah tangga (50\%) tidak mengetahui permukaan sikat gigi yang baik adalah permukaan bulu sikat gigi yang rata atau datar. Menurut Chumbley, J dan Walters, C (2003) sikat gigi yang benar yaitu:

a) Bulu sikat gigi lembut dan kepala sikat harus kecil sehingga mempermudah anak dalam menyikat gigi gigi belakang.

b) Permukaan sikat gigi harus rata.

c) Sikat gigi orang dewasa tidak cocok untuk anak kecil karena kepala sikat terlalu besar.

d) Jenis sikat gigi dengan pegangan harus sesuai.

e) Simpan sikat dalam pisisi tegak sehingga bulu sikat dapat mongering dan tidak saling bersentuhan dengan sikat gigi lain. f) Ganti sikat gigi anak bila telah ada tanda kerusakan.

Terdapat 10 ibu rumah tangga (33,3\%) yang tidak mengetahui bahwa lama waktu menyikat gigi yang baik yaitu dua sampai lima menit. Menurut Manson (1971) bahwa mengosok gigi sekurang-kurangnya dua kali sehari, setelah sarapan pagi dan sebelum tidur malam, lama menyikat gigi dua sampai lima menit.

2. Status keadaan gigi pada anak di Tk Ra.Al-Hasanah Jl.Bunga Melati Kemenangan Tani Kecamatan Medan Tuntungan.

Dari 30 siswa yang diteliti ditemukan 91 gigi yang mengalami berlubang (3\%) atau jumlah gigi yang terkena karies (decay). Karies gigi merupakan suatu penyakit yang mengenai jaringan keras gigi, yaitu email, denti dan sementum, adapun daerah yang membusuk pada gigi, terjadi karena proses yang secara bertahap melarutkan mineral permukaan gigi dan terus berkembang kebagian dalam gigi (medicastrore.com, 2007). Dari 30 siswa ditemukan 20 siswa giginya yang telah tercabut 29 gigi (96\%) karena karies dan harus dicabut karena sebah lain (extraction).

\section{Kesimpulan}

Berdasarkan hasil penelitian yang telah dilakukan pada 30 ibu rumah tangga menyikat gigi secara dini pada anak terhadap nilai def-t di TK-Islam Terpadu Ra.Al-Hasanah Jl.Bunga Melati Kemenangan Tani Kecamatan Medan Tuntungan 2018, maka dapat diambil kesimpulan yaitu:

1. Tingkat pengetahuan ibu tentang menyikat gigi secara dini pada anak seberapa besar pemahaman ibu tentang pentingnya menyikat gigi. Dan dikategorikan baik sebayak 25 (83,3\%), lima orang yang memiliki kategori sedang (17\%) dan tidak ada yang memiliki kategori buruk dalam tikat pengetahuan ibu.

2. Nilai def-t atau status gigi pada anak Tk-Islam Terpadu Ra.Al-Hasanah yaitu kategori gigi yang berlubang atau decay 91 (3,6\%), kategori gigi yang dicabut karena karies dank arena sebab lain atau extraction 29 (96,6\%), dan kategori filling tidak ada di temukan karena belum pernah dilakukan perawatan.

\section{Saran}

1. agar ibu memperhatikan cara menyikat gigi yang baik dan benar dan memilih sikat gigi dengan permukaan bulu sikat yang rata dan tidak keras.

2. agar pihak sekolah berkerja sama dengan petugas kesehatan gigi dan mulut melaksanakan program UKGS.

3. agar orang tua memeriksakan gigi anaknya ke dokter gigi atau pelayanan kesehatan gigi dan mulut secara teratur minimal enam bulan sekali.

\section{DAFTAR PUSTAKA}

Afriani , G dan gracinia, j. 2006, 75 Masalah Gigi Anak dan Solusinya, Elek media komputindo, Jakarta. 
Pratiwi, D. 2009, Gigi Sehat dan Cantik, kompas media nusantara, Jakarta.

Machfoedz, I. 2008, menjaga Kesehatan Gigi dan Mulut Anak-Anak Dan Ibu Hamil, fitramaya, Yogyakarta.

Notoatmodjo, S. 2010, Metode Penelitian Kesehatan, rineka cipta, Jakarta.

. 2007, Promosi Kesehatan dan Ilmu Perilaku, rineka cipta, Jakarta.
. 2005, Promosi Kesehatan Teori dan Aplikasi, rineka cipta, Jakarta.

. 2003, Pendidikan dan Perilaku Kesehatan, rineka cipta, Jakarta.

Srigupta , A. 2004, Perawatan Gigi dan Mulut, prestasi pustaka, Jakarta. 